\title{
Somatotopic fascicular organization of the human sciatic nerve demonstrated by MR neurography OPEN
}

Philipp Bäumer, MD Markus Weiler, MD Martin Bendszus, MD Mirko Pham, MD

Correspondence to Dr. Bäumer: philipp.baeumer@ med.uni-heidelberg.de

\section{ABSTRACT}

Objectives: To investigate whether the human sciatic nerve might have a consistent somatotopic organization according to proximal fascicle input by spinal nerves.

Methods: Twelve patients ( $55.3 \pm 15.5$ years) with confirmed lesions of either the L5 or S1 spinal nerve root underwent magnetic resonance neurography of sciatic nerve fascicles including thigh and knee levels (T2-weighted sequence with fat saturation, repetition time/echo time 7,552/52 milliseconds, voxel size $0.27 \times 0.27 \times 3.0 \mathrm{~mm}^{3}$ ). Twenty healthy subjects and 12 additional patients with an established diagnosis of peripheral polyneuropathy served as 2 separate age- and sex-matched control groups. Two blinded readers assessed patients and controls for presence of distinct lesion patterns. Spatial maps of normalized T2 signal were rendered after segmentation and coregistration of sciatic nerve voxels to detect fascicle lesion patterns.

Results: A clear somatotopic distribution of nerve fascicles was observed on cross-sections along the entire course of the sciatic nerve and was distinct between patients with $L 5$ and those with S1 lesions. Fascicles emerging from L5 were ordered in anterolateral positions within sciatic nerve cross-sections, while fascicles emerging from S1 appeared posteromedially. Visual assessment discriminated these somatotopic lesions in all cases from both healthy and polyneuropathy controls.

Conclusion: A distinct pattern of somatotopy was identified within the sciatic nerve according to proximal fascicle input by L5 and S1 spinal nerves. Knowledge of human nerve somatotopy may have clinically useful implications in imaging-aided diagnosis of neuropathies. Neurology ${ }^{\circledR}$ 2015;84:1782-1787

\section{GLOSSARY}

MRN = magnetic resonance neurography; PNP = polyneuropathy

The somatotopic organization of the CNS has been investigated in detail but little is known about the internal topography of peripheral nerves. The classic works by Sunderland ${ }^{1}$ posited the idea of widespread "plexiform" intermingling of fascicles within a given nerve. These results questioned the concept of an interindividually consistent somatotopy, that is, a reproducible topographic organization of fascicles within peripheral nerves. Subsequent studies, however, collected evidence for a high degree of spatial preservation of nerve fascicles positioning in crosssection. ${ }^{2}$ These mainly experimental reports investigated the more accessible, distal portions of peripheral nerves ex vivo and found a consistent somatotopic ordering of fascicles in a "cablelike" fashion, which corresponded to the spatial-anatomical arrangement of supplied target muscles and skin areas. ${ }^{2}$ Whether nerve topography might also follow an internal somatotopic pattern according to proximal fascicular input by spinal nerves has not been examined in humans.

Detection of partial and somatotopically ordered lesions in peripheral nerves can be of significant diagnostic value as was recently shown by visualization of proximal median nerve lesions

From the Departments of Neuroradiology (P.B., M.B., M.P.) and Neurology (M.W.), Heidelberg University Hospital, Germany.

Go to Neurology.org for full disclosures. Funding information and disclosures deemed relevant by the authors, if any, are provided at the end of the article. The Article Processing Charge was paid by the Department of Neuroradiology of Heidelberg University Hospital.

This is an open access article distributed under the terms of the Creative Commons Attribution-Noncommercial No Derivative 3.0 License, which permits downloading and sharing the work provided it is properly cited. The work cannot be changed in any way or used commercially. 
isolated to motor fascicles in anterior interosseous neuropathy. ${ }^{3}$ In this series, we report in vivo findings from magnetic resonance neurography (MRN), demonstrating by fascicular lesion topography the somatotopy of the sciatic nerve, according to proximal contribution from L5- or S1-derived nerve roots and spinal nerves.

METHODS Standard protocol approvals, registrations, and patient consents. This observational study was approved by the institutional ethics committee (S-057/2009) and written informed consent was obtained from all participants.

Patient inclusion criteria and control groups. Nine patients with an established diagnosis of L5 radiculopathy or spinal nerve lesion and 3 patients with an established S1 radiculopathy or spinal nerve lesion were included. Since nerves can be damaged at any point from their exit from the spinal cord as ventral and dorsal nerve rootlets and roots, which then enter the vertebral foramen to form the spinal nerve, we here subsume these different anatomical segments under the term "spinal nerve root." Likewise, corresponding preforaminal, intraforaminal, and postforaminal lesion sites are subsumed further as "radiculopathy" (including proximal spinal nerve lesions) to distinguish them from sciatic mononeuropathies occurring distal to plexus formation. Confirmation of diagnosis in patients was based on a combination of clinical, electrophysiologic, and imaging findings: paresis (medical research council grade $\leq 4$ ) in L5 or S1 innervated muscles ${ }^{4}$; evidence of myotomal denervation on EMG and exclusion of large fiber polyneuropathy (PNP) on electroneurography according to standard practice recommendations; ; spine and plexus MRI results, and in cases of traumatic injuries involving fractures also CT; and lower leg muscle denervation patterns consistent with either L5 or S1 spinal nerve root affection on MRI. ${ }^{6}$

Twenty age-matched healthy subjects ( 10 women, 10 men, $50.3 \pm 11.6$ years) without symptoms of peripheral neuropathy, or risk factors such as diabetes, alcoholism, or infectious disease served as healthy controls for quantitative and qualitative analysis. Another 12 patients ( 6 women, 6 men, $54.6 \pm 14.1$ years) with confirmed diagnosis of PNP $(5 \times$ chronic inflammatory demyelinating PNP, $2 \times$ monoclonal gammopathy-associated PNP, $1 \times$ each multifocal acquired demyelinating sensory and motor neuropathy, multifocal motor neuropathy, hereditary motor and sensory neuropathy I, uremic PNP, graft-vs-host disease-associated PNP), but not typical symptoms of L5 or S1 radiculopathy, were included as a second control group for qualitative analysis.

MRN protocol. Patients were examined at the Department of Neuroradiology of Heidelberg University Hospital, Germany, between May 2010 and July 2014. MRN examinations at 3T (Magnetom VERIO; Siemens, Erlangen, Germany) were performed with axial high-resolution T2-weighted fat-saturated

\begin{tabular}{|c|c|c|c|c|c|c|c|c|}
\hline Table & Cli & nical c & data of pati & & & & & \\
\hline \multirow[b]{2}{*}{ No. } & \multirow[b]{2}{*}{ Age, y } & \multirow[b]{2}{*}{ Sex } & \multirow{2}{*}{$\begin{array}{l}\text { Affected } \\
\text { spinal } \\
\text { nerve root }\end{array}$} & \multirow{2}{*}{$\begin{array}{l}\text { Muscle } \\
\text { strength }\end{array}$} & \multirow{2}{*}{$\begin{array}{l}\text { Duration of } \\
\text { symptoms before } \\
\text { MRI, mo }\end{array}$} & \multicolumn{2}{|c|}{$\begin{array}{l}\text { Localization of lesion } \\
\text { by }\end{array}$} & \multirow[b]{2}{*}{ Diagnosis } \\
\hline & & & & & & Imaging & Surgery & \\
\hline & & & & $\begin{array}{l}\text { Foot and toe } \\
\text { extension }\end{array}$ & & & & \\
\hline 1 & 73 & $\mathrm{~F}$ & L5 & $0 / 5$ and $0 / 5$ & 5 & $\begin{array}{l}\text { Spine and } \\
\text { plexus MRI }\end{array}$ & Yes & Disk herniation L4-5 \\
\hline 2 & 55 & M & L5 & $4 / 5$ and $3 / 5$ & 3 & $\begin{array}{l}\text { Spine and } \\
\text { plexus MRI }\end{array}$ & Yes & Disk herniation L4-5 \\
\hline 3 & 72 & $\mathrm{~F}$ & L5 & $0 / 5$ and $0 / 5$ & 6 & $\begin{array}{l}\text { Spine and } \\
\text { plexus MRI }\end{array}$ & None & Extraforaminal/far lateral disk herniation L5-S1 \\
\hline 4 & 44 & M & L5 & $4 / 5$ and $4 / 5$ & 1 & $\begin{array}{l}\text { Spine and } \\
\text { plexus MRI }\end{array}$ & Yes & Extraforaminal/far lateral disk herniation L5-S1 \\
\hline 5 & 65 & M & L5 & $1 / 5$ and $1 / 5$ & 6 & Plexus MRI & None & $\begin{array}{l}\text { Inflammatory radiculopathy (varicella zoster virus, CSF } \\
\text { confirmed) }\end{array}$ \\
\hline 6 & 29 & $\mathrm{~F}$ & L5 & $0 / 5$ and $0 / 5$ & 3 & $\begin{array}{l}\text { CT/plexus } \\
\text { MRI }\end{array}$ & Yes & $\begin{array}{l}\text { latrogenic } L 5 \text { compression by screw instrumentation after } \\
\text { pelvic fracture }\end{array}$ \\
\hline 7 & 73 & $\mathrm{~F}$ & L5 & $3 / 5$ and $2 / 5$ & 4 & $\begin{array}{l}\text { Spine and } \\
\text { plexus MRI }\end{array}$ & None & $\begin{array}{l}\text { L5 radiculopathy due to degenerative changes with scoliosis } \\
\text { and intraforaminal nerve compression }\end{array}$ \\
\hline 8 & 54 & $\mathrm{~F}$ & L5 & $2 / 5$ and $2 / 5$ & 6 & $\begin{array}{l}\text { Spine and } \\
\text { plexus MRI }\end{array}$ & None & $\begin{array}{l}\text { Isolated L5 neuropathy, syndrome of undetermined etiology } \\
\text { with unequivocal clinical presentation and plexus imaging }\end{array}$ \\
\hline \multirow[t]{2}{*}{9} & 74 & M & L5 & $4 / 5$ and $4 / 5$ & 2 & $\begin{array}{l}\text { Spine and } \\
\text { plexus MRI }\end{array}$ & None & Extraforaminal disk herniation L5-S1 \\
\hline & & & & Plantar flexion & & & & \\
\hline 10 & 51 & M & s1 & $4 / 5$ & 12 & $\begin{array}{l}\text { CT/plexus } \\
\text { MRI }\end{array}$ & Yes & $\begin{array}{l}\text { latrogenic } \mathrm{S} 1 \text { lesion by screw instrumentation after pelvic } \\
\text { fracture }\end{array}$ \\
\hline 11 & 34 & M & s1 & $4 / 5$ & 2 & $\begin{array}{l}\text { Spine and } \\
\text { plexus MRI }\end{array}$ & None & $\begin{array}{l}\text { Intrathecal cytarabine-associated sacral radiculopathy in T- } \\
\text { ALL }\end{array}$ \\
\hline 12 & 52 & $\mathrm{~F}$ & S1 & $3 / 5$ & 3 & Plexus MRI & Yes & latrogenic S1 lesion during hysteropexia \\
\hline
\end{tabular}

Diagnosis was based on clinical examination with electrophysiology, as well as direct imaging confirmation by MRI of the spine and plexus (and CT in 2 cases with nerve lesions by metallic instrumentation). 
section blocks (repetition time/echo time 7,552/52 milliseconds, spectral fat saturation, acquisition time 7:07 minutes, matrix $512 \times 358$, field of view $140 \mathrm{~mm}$, voxel size $0.27 \times 0.27 \times$ $3.0 \mathrm{~mm}^{3}$, interslice gap $0.3 \mathrm{~mm}$, slices 45 for each slab) using an 8-channel phased-array extremity coil (Siemens) to cover the sciatic nerve and its branches at thigh and knee levels. Calf muscles were scanned after patient and coil repositioning using the same sequence. Additional imaging in all patients covered the lumbosacral plexus from L3 spinal nerves to at least the sciatic notch with a 3-dimensional turbo spin echo with variable flip-angle sequence (repetition time/echo time/inversion time 3,800/266/180 milliseconds, acquisition time 8:32 minutes, matrix $320 \times 320$, field of view $305 \mathrm{~mm}$, voxel size $0.95 \times$ $0.95 \times 1.0 \mathrm{~mm}^{3}$, slices 104) using a $2 \times 6$ channel flexible body surface array coil and 12-channel spine array.

Postprocessing and image analysis. Sciatic nerve crosssections for each patient were taken at a representative position $17 \mathrm{~cm}$ proximal to the knee joint space. Fibular and tibial nerve divisions were segmented separately and aligned since they divide at interindividually different levels. Images were flipped horizontally from left to right in patients with left-sided symptoms to achieve anatomical comparability. For generation of spatial representation maps on group level, intersubject image registration was performed with 6 degrees of freedom (FMRIB [Oxford Centre for Functional Magnetic Resonance Imaging of the Brain] Software Library version 5.0). Signal normalization was achieved by calculating the ratio between nerve T2 signal and T2 signal of adjacent nondenervated muscle on the corresponding slice. Then, spatial maps of mean normalized T2 values were rendered for patients.
Sciatic nerve images were rated for each subject by 2 investigators (P.B., M.P.) blinded to the diagnosis into one of the following lesion pattern categories: (1) normal, (2) disseminated lesion pattern, or (3) somatotopic lesion pattern. If a subject was rated as having a somatotopic lesion pattern, it was further rated as either L 5 or S1 pattern. Only images containing the sciatic nerve at thigh and knee level were used for this, since more proximal or more distal images might have disclosed the diagnosis (e.g., by revealing root compression or distal denervation patterns).

RESULTS Patient data. Twelve patients $(55.3 \pm 15.5$ years) were included with lesions of either the L5 (9 patients) or S1 (3 patients) spinal nerve root (table). Diagnosis was based on clinical presentation with EMG results, and imaging of the spine and lumbosacral plexus additionally localized the lesion in all cases to the corresponding L5 or S1 spinal nerve root. Surgery was subsequently performed in 6 patients and further confirmed imaging findings.

Somatotopy of spatial lesion patterns in sciatic nerve. In all cases of L5 radiculopathy, lesion extension along the longitudinal course of sciatic nerve fascicles followed a distinct internal pattern of topographic organization within the nerve cross-section (figure 1). Ventral and lateral fascicles in the sciatic nerve displayed pathologically increased T2 signal, while dorsal fascicles were normal.

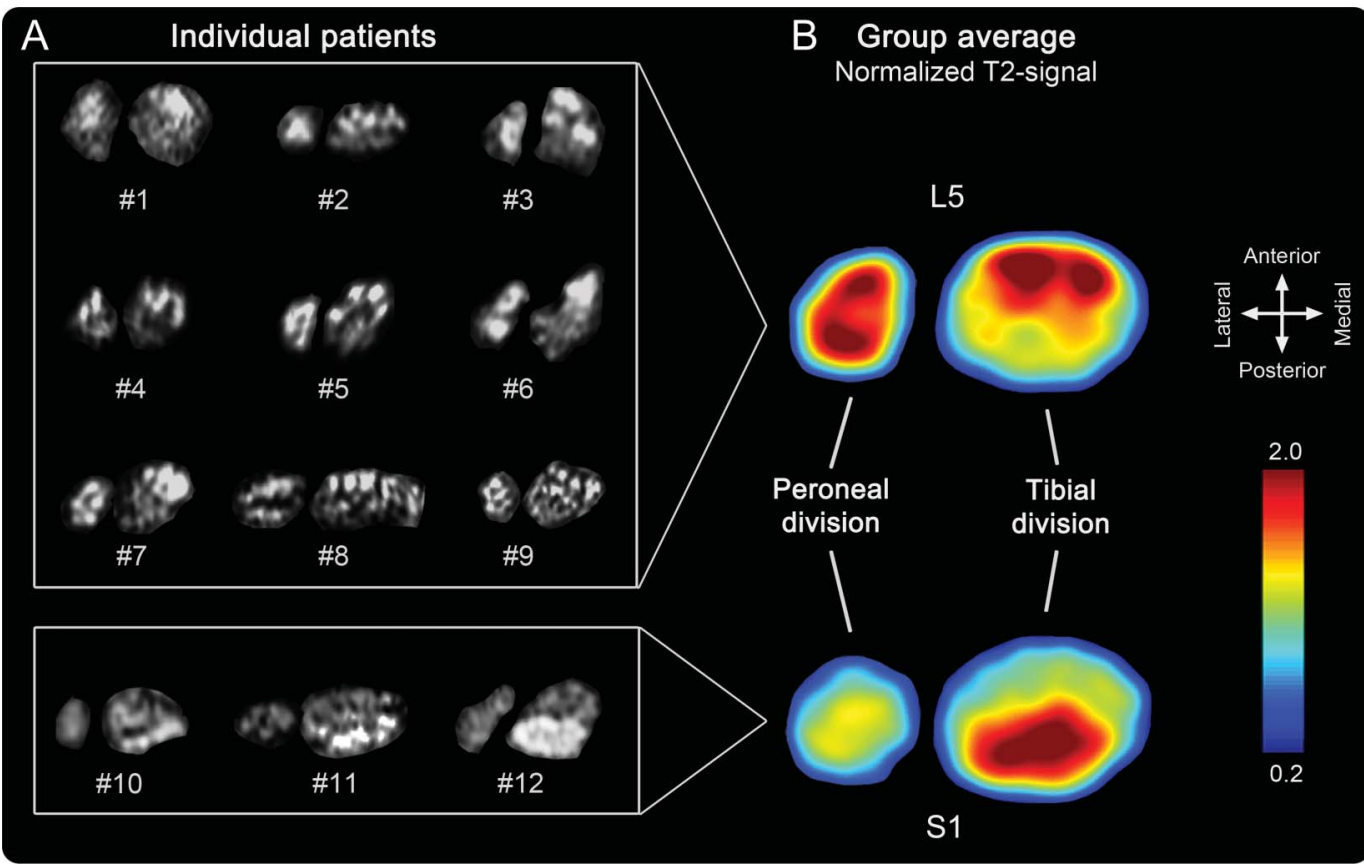

(A) Complete array of representative axial images of the sciatic nerve for each patient, at thigh level $17 \mathrm{~cm}$ proximal to the knee joint space. Lesioned fascicles within sciatic nerve are located anterolateral in patients with L5 neuropathy and posteromedial in patients with S1 neuropathy. Images are flipped horizontally from left to right in patients with left-sided affection to obtain comparability. Fibular and tibial divisions are separated from each other since they divide at different levels interindividually. (B) Color-coded spatial map of pathologically increased T2 signal, calculated as the group mean after intersubject image registration with 6 degrees of freedom. Note that, because of the calculation mode by relative signal intensity values, this map serves for visualization purposes alone and not as a fully quantitative probability map. 
In all cases of S1 radiculopathy, lesion extension along the longitudinal course of sciatic nerve fascicles again followed a distinct pattern of topographic organization, affecting predominantly dorsal fascicles. L5 and S1 lesions appeared complementary and congruent to each other with little spatial overlap. Lesion patterns were delineated in cross-sections of the sciatic nerve along its entire length until knee level (figure 2).

At calf level, muscle denervation patterns were consistent with the diagnosis of L5 and S1 lesions ${ }^{6,7}$ and corresponded to the somatotopic lesion pattern within the sciatic nerve.

Differential diagnosis by pattern discrimination. Somatotopic lesion distribution was discriminated against normal (healthy control group) and disseminated (PNP control group) lesion patterns by qualitative visual assessment with high diagnostic accuracy and strong interobserver agreement. All 12 sciatic nerves with L5 or S1 lesions were correctly rated as somatotopic lesions, and all 12 PNP controls correctly as disseminated neuropathy by both readers. Further discrimination of somatotopic lesion patterns into etiologies of L5 vs S1 lesions was correct in all cases. Healthy controls were correctly rated normal in $17 / 20$ and 16/20 cases and falsely rated positive in
$3 / 20$ and 4/20 as PNP by rater 1 and 2, respectively (overall Cohen $\kappa=0.95$ ), resulting in a specificity of $82.5 \%$ and a sensitivity of $100 \%$.

DISCUSSION We here report in vivo evidence of the somatotopic organization of the human sciatic nerve according to its main proximal contributors, the L5 and S1 spinal nerve roots. Apparently, sciatic nerve fascicles maintain a clearly arranged spatial position within the nerve cross-section depending on their origin from spinal nerve roots, not only within the proximal nerve trunk but even until the bifurcation of the sciatic nerve.

These findings strongly support the idea of a mainly "cable-like" structure within peripheral nerves. Previous investigations on the internal arrangement of the sciatic nerve have been undertaken in great anatomical detail and have unraveled the somatotopy of the sciatic nerve regarding distal innervation targets. ${ }^{8-10}$ Our study is to our knowledge the first to support the existence of a reproducible somatotopy within human peripheral nerves in vivo and according to their proximal input. The only available experimental animal study exploring this idea, with cadaver dissection of dogs after selective spinal

Figure 2 Longitudinal array of distinct sciatic nerve lesion patterns

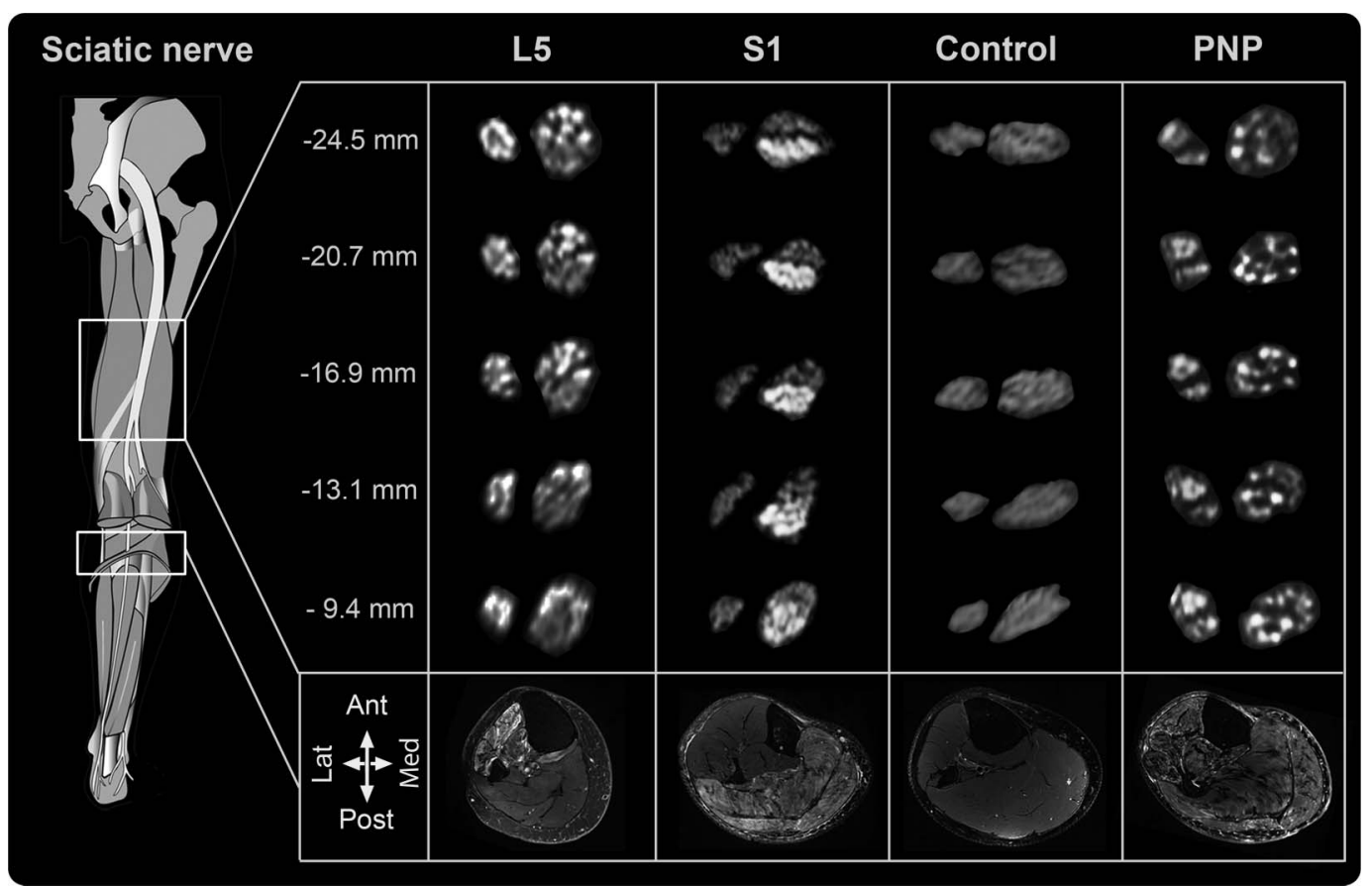

Sciatic nerve cross-sections level of exemplary patients are shown at different thigh levels. Precise spatial position is given in millimeters proximal to the knee joint by cross-referencing with MRI localizers. Left smaller divisions correspond to fibular, right divisions to tibial division of the sciatic nerve. L5 lesions are associated with T2-weighted hyperintense anterolateral fascicles; S1 lesions are obvious in posterior fascicles along the course of the sciatic nerve. Healthy controls do not exhibit nerve lesions, whereas polyneuropathies (PNPs) (case of multifocal motor neuropathy shown above) have short, discontinuous scattered lesion in an apparently random fashion. Muscle denervation corresponds to lesion patterns in nerves. In L5 lesions, mainly the extensor and fibular compartment is affected as well as the posterior tibial and popliteal muscle. In S1 lesions, soleus and gastrocnemius muscles are mainly affected. In diffuse PNP, all muscles can be affected. 
nerve section, found a longitudinally retained topography of spinal nerve-dependent arrangement within the sciatic nerve. ${ }^{11}$ Our in vivo findings in patients are entirely consistent with this previous animal study and demonstrate the concept of a "radicular" peripheral nerve somatotopy in human neuroanatomy.

Knowledge of sciatic nerve somatotopy and imaging of selective fascicular lesions can have clinical significance in a number of different situations. ${ }^{3}$ Differentiation of radiculopathies from inflammatory or metabolic sciatic neuropathies is a frequently encountered clinical situation. Although expert electrodiagnostic examinations will most often lead to the correct diagnosis in common radiculopathies, needle electrode examinations are still subject to patient compliance, and time-dependence of needle electrode examinations, which may partially normalize over time. ${ }^{5}$ Furthermore, partial spinal nerve root lesions involving, e.g., only motor or only sensory fascicles, and interindividual variation in dermatomal and myotomal arrangement are phenomena that can complicate clinical and electrophysiologic assessment. ${ }^{12-14}$ Innervation anomalies and pure demyelinating lesions not leading to wallerian degeneration or pure sensory disturbances without EMG findings can also pose diagnostic difficulties. The latter 2 scenarios would only cause alterations in somatosensory evoked potentials or F waves that both have a limited topodiagnostic resolution. In all of these situations, detection of somatotopic lesions of the sciatic nerve at thigh level would yield additional diagnostic certainty. Future studies will have to investigate precisely in which clinical circumstances additional MRN provides added value.

The current study has limitations. The small patient number does not yet allow full external generalization of our somatotopic map of the sciatic nerve. This is especially true for the fibular portion of the sciatic nerve, which only shows minor lesions in our cases but is known to carry fascicles stemming from the S1 spinal nerve. Furthermore, we acknowledge that we cannot exclude some degree of intermingling between proximal nerve fibers. However, potential plexiform intermingling is apparently limited to such a degree that conspicuous T2 lesions on MRI appear regionally restricted so that the somatotopic distribution is conserved. Experimental studies have shown that nerve degeneration by proximal lesions results in distally increased nerve T2 signal. ${ }^{15}$ The appearance of T2 signal alterations in distal nerve segments after proximal lesions is likely to depend on the severity of the lesion and time. Severe proximal lesions may appear within a few days. ${ }^{15}$ Less severe damage, which is more difficult to simulate experimentally, might take months to become visible. Future studies will need to investigate this time and stimulus dependence of distal T2 lesion appearance by proximal injury.

The somatotopic organization of fascicles within the human sciatic nerve according to its proximal input from spinal nerve roots L5 and S1 is demonstrated here in vivo by MRN. These lesions can be readily discriminated from healthy subjects and PNPs. This work therefore supports a robust somatotopic organization in peripheral nerve trunks according to proximal radicular input with clinically relevant diagnostic implications for lesion localization in the peripheral nervous system.

\section{AUTHOR CONTRIBUTIONS}

Philipp Bäumer: study design, acquisition of data, analysis and interpretation of data, drafting/revising the manuscript for content. Markus Weiler: acquisition of data, analysis and interpretation of data, drafting/revising the manuscript for content. Martin Bendszus: study design, drafting/revising the manuscript for content, study supervision. Mirko Pham: study design, acquisition of data, analysis or interpretation of data, drafting/revising the manuscript for content.

\section{ACKNOWLEDGMENT}

The authors thank Annie Xia for the artwork in figure 2.

\section{STUDY FUNDING}

P.B. was supported by a postdoctoral fellowship from the Medical Faculty of the University of Heidelberg. M.P. was supported by a memorial stipend of the Else-Kröner-Fresenius Foundation and a grant from the EFSD/JDRF/Novo Nordisk European Programme in Type 1 Diabetes Research.

\section{DISCLOSURE}

The authors report no disclosures relevant to the manuscript. Go to Neurology.org for full disclosures.

Received November 29, 2014. Accepted in final form January 15, 2015.

\section{REFERENCES}

1. Sunderland S. Nerves and Nerve Injuries. New York: Churchill Livingstone; 1978.

2. Stewart JD. Peripheral nerve fascicles: anatomy and clinical relevance. Muscle Nerve 2003;28:525-541.

3. Pham M, Baumer P, Meinck HM, et al. Anterior interosseous nerve syndrome: fascicular motor lesions of median nerve trunk. Neurology 2014;82:598-606.

4. Compston A. Aids to the investigation of peripheral nerve injuries. Medical Research Council: Nerve Injuries Research Committee. His Majesty's Stationery Office: 1942; pp. 48 (iii) and 74 figures and 7 diagrams; with aids to the examination of the peripheral nervous system. By Michael O'Brien for the Guarantors of Brain. Saunders Elsevier: 2010; pp. [8] 64 and 94 Figures. Brain 2010;133:2838-2844.

5. Wilbourn AJ, Aminoff MJ. AAEM minimonograph 32: the electrodiagnostic examination in patients with radiculopathies. American Association of Electrodiagnostic Medicine. Muscle Nerve 1998;21:1612-1631.

6. Bendszus M, Wessig C, Reiners K, Bartsch AJ, Solymosi L, Koltzenberg M. MR imaging in the differential diagnosis of neurogenic foot drop. AJNR Am J Neuroradiol 2003;24:1283-1289.

7. Kim SJ, Hong SH, Jun WS, et al. MR imaging mapping of skeletal muscle denervation in entrapment and compressive neuropathies. Radiographics 2011;31:319-332. 
8. McKinley JC. The intraneural plexus of fasciculi and fibers in the sciatic nerve. Arch Neurol Psychiatr 1921;6: 377-399.

9. Sunderland S, Ray LJ. The intraneural topography of the sciatic nerve and its popliteal divisions in man. Brain 1948; 71:242-273.

10. Gustafson KJ, Grinberg Y, Joseph S, Triolo RJ. Human distal sciatic nerve fascicular anatomy: implications for ankle control using nerve-cuff electrodes. J Rehabil Res Dev 2012;49:309-321.

11. Ueyama T. The topography of root fibres within the sciatic nerve trunk of the dog. J Anat 1978;127:277-290
12. Lee MW, McPhee RW, Stringer MD. An evidence-based approach to human dermatomes. Clin Anat 2008;21: 363-373.

13. Phillips LH II, Park TS. Electrophysiologic mapping of the segmental anatomy of the muscles of the lower extremity. Muscle Nerve 1991;14:1213-1218.

14. Friis ML, Gulliksen GC, Rasmussen P, Husby J. Pain and spinal root compression. Acta Neurochir 1977;39:241-249.

15. Bendszus M, Wessig C, Solymosi L, Reiners K, Koltzenburg M. MRI of peripheral nerve degeneration and regeneration: correlation with electrophysiology and histology. Exp Neurol 2004;188:171-177.

\section{Pit Neurology.org Offers Important Information to Patients and Their Families}

The Neurology ${ }^{\circledR}$ Patient Page provides:

- A critical review of ground-breaking discoveries in neurologic research that are written especially for patients and their families

- Up-to-date patient information about many neurologic diseases

- Links to additional information resources for neurologic patients

All Neurology Patient Page articles can be easily downloaded and printed, and may be reproduced to distribute for educational purposes. Click on the 'Patients' link on the home page (Neurology.org) for a complete index of Patient Pages.

\section{Neurology ${ }^{\circledR}$ Genetics Call For Papers}

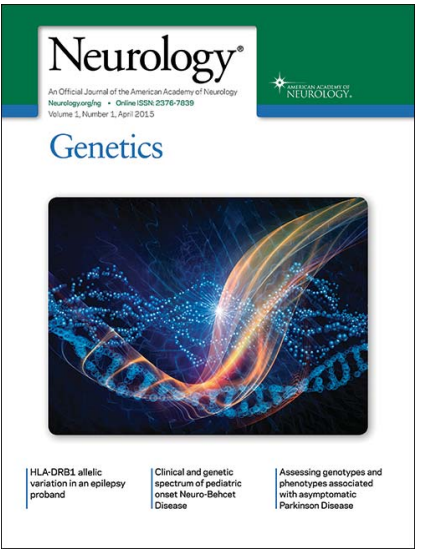

Neurology: Genetics is an open access, online only journal that will provide neurologists with outstanding original contributions that elucidate the role of genetic and epigenetic variation in diseases and biological traits of the central and peripheral nervous system. We welcome all submissions. For more information on how to submit, visit http://www.neurology.org/site/ gen/gen2.xhtml. 


\section{Neurology}

\section{Somatotopic fascicular organization of the human sciatic nerve demonstrated by MR neurography}

Philipp Bäumer, Markus Weiler, Martin Bendszus, et al.

Neurology 2015;84;1782-1787 Published Online before print April 3, 2015

DOI 10.1212/WNL.0000000000001526

\section{This information is current as of April 3, 2015}

\section{Updated Information \& Services}

References

Citations

Subspecialty Collections

Permissions \& Licensing

Reprints including high resolution figures, can be found at: http://n.neurology.org/content/84/17/1782.full

This article cites 14 articles, 1 of which you can access for free at: http://n.neurology.org/content/84/17/1782.full\#ref-list-1

This article has been cited by 3 HighWire-hosted articles: http://n.neurology.org/content/84/17/1782.full\#\#otherarticles

This article, along with others on similar topics, appears in the following collection(s):

\section{Disc disease}

http://n.neurology.org/cgi/collection/disc_disease

\section{MRI}

http://n.neurology.org/cgi/collection/mri

Peripheral neuropathy

http://n.neurology.org/cgi/collection/peripheral_neuropathy

Information about reproducing this article in parts (figures,tables) or in its entirety can be found online at:

http://www.neurology.org/about/about_the_journal\#permissions

Information about ordering reprints can be found online:

http://n.neurology.org/subscribers/advertise

Neurology ${ }^{\circledR}$ is the official journal of the American Academy of Neurology. Published continuously since 1951, it is now a weekly with 48 issues per year. Copyright @ 2015 American Academy of Neurology. All rights reserved. Print ISSN: 0028-3878. Online ISSN: 1526-632X.

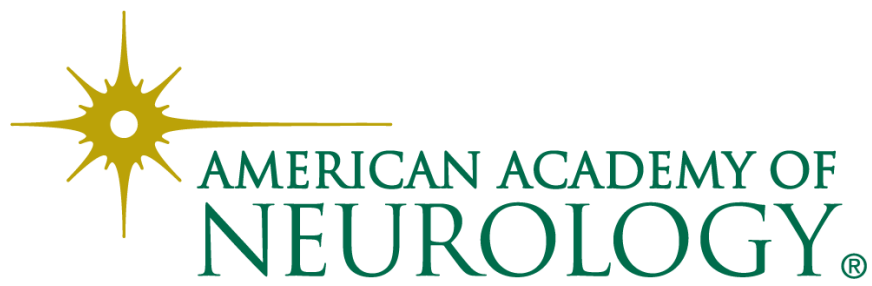

